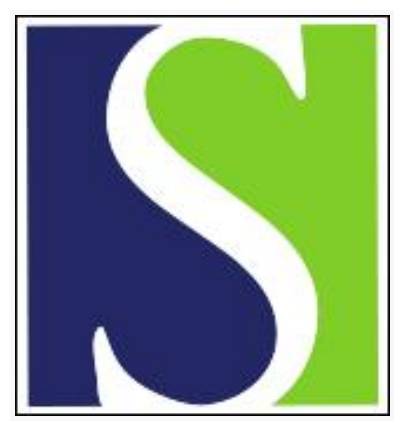

Scand J Work Environ Health 2009;35(6):446-453

https://doi.org/10.5271/sjweh.1358

Published online: 01 Oct 2009, Issue date: 00 Dec 2009

Cancer incidence among large cohort of female Danish registered nurses

by Kjaer TK, Hansen J

Affiliation: Institute of Cancer Epidemiology, Danish Cancer Society, Copenhagen, Denmark. trille@cancer.dk

Refers to the following texts of the Journal: 1999;25 suppl 2:1-116 2007;33(1):66-73

Key terms: cancer; cancer incidence; cohort study; Denmark; nurse; registered nurse; shift work; woman

This article in PubMed: www.ncbi.nlm.nih.gov/pubmed/19806273 


\title{
Cancer incidence among a large cohort of female Danish registered nurses
}

\author{
by Trille Kristina Kjaer, MSc, ${ }^{1}$ Johnni Hansen, $P h D^{2}$
}

\author{
Kjaer TK, Hansen J. Cancer incidence among a large cohort of female Danish registered nurses. Scand J Work \\ Environ Health. 2009;35(6):446-453.
}

\begin{abstract}
Background Nurses are potentially exposed to carcinogens in their working environment. We investigated the risks for 21 types of cancers in Danish nurses.

Methods We identified 92140 female nurses from the computerized files of the Danish Nurses' Association. By record linkage, we reconstructed information on employment since 1964 using data from a national pension fund; information on vital status and reproduction was obtained from the Central Population Register. Each woman was followed-up from 1980-2003 in the Danish Cancer Registry. We calculated standardized incidence ratios (SIR) and 95\% confidence intervals (95\% CI). Using Poisson regression models, we made internal comparisons in subgroups of nurses, adjusting for potential confounders.
\end{abstract}

Results We documented 8410 cancers during follow-up and found significantly increased SIR for breast cancer (SIR 1.1, 95\% CI 1.1-1.2), cancers of the brain and nervous system (SIR 1.2, 95\% CI 1.1-1.3), melanoma (SIR 1.2, 95\% CI 1.1-1.3), and other skin cancers (SIR 1.2, 95\% CI 1.1-1.2). Significantly decreased risks were observed for alcohol- and tobacco-related cancers. Nurses who were accredited by the Association after 1981 had significantly increased risks for thyroid cancer (SIR 1.9, 95\% CI 1.3-2.5) and cancers of the brain and nervous system (SIR 1.5, 95\% CI 1.2-1.9). Former nurses had significantly increased SIR for all cancers combined and breast cancer the first ten years after leaving the profession. In a Poisson regression analysis of breast cancer and duration of employment in hospitals, adjusted for reproductive factors, nurses had an increase risk the first 25 years of employment, but not for longer periods.

Conclusion The increased risk of breast cancer and the decreased risk of alcohol- and tobacco-related cancers support the findings of most other studies on nurses. The elevated risks for cancers of the breast, brain, nervous system, and thyroid warrant further study.

Key terms cohort study; shift work.

Numerous studies have addressed the risk of cancer for healthcare workers, as they are exposed to a number of biological, chemical, physical, and psychological health hazards in their work environment. Some of these hazards have been classified by working groups convened by the International Agency for Research on Cancer (IARC) as either "carcinogenic" or "probable carcinogenic" [eg, ionizing radiation (1), antineoplastic drugs (2), anesthetic waste gases (3), and ethylene oxide (4)]. More recently, an IARC working group classified shift work that involves circadian disruption as a probable cause of breast cancer (5).

Most previous studies of nurses have included limited data on employment history and confounding factors, focused on few cancers only, or been relatively small (6-10).

In this large cohort study of female Danish nurses, we investigated the risks for 21 different cancers by duration of employment as a nurse and in different generations of nurses - reflecting historical and behavioral differences in the nursing profession. We also studied the subgroup of nurses who have left the nursing profession. Finally, since employment in hospitals usually involves shift work, we further focused on breast cancer and the duration of employment in hospitals (8).

1 Department of Psychosocial Cancer Research, Institute of Cancer Epidemiology, Danish Cancer Society, Copenhagen Ø, Denmark.

2 Department of Occupational Cancer, Institute of Cancer Epidemiology, Danish Cancer Society, Copenhagen Ø, Denmark.

Correspondence to: TK Kjaer, Institute of Cancer Epidemiology, Danish Cancer Society, Strandboulevarden 49, 2100 Copenhagen $\varnothing$, Denmark. [E-mail: trille@cancer.dk] 


\section{Material and methods}

\section{Study population and data sources}

This study is based on computerized records for 92140 women with a Danish nursing accreditation who were members of the Danish Nurses' Association when records became computerized in April 1980, and new members thereafter until the end of 2001. The Association covers about $95 \%$ of Danish nurses. From these data, we extracted the names, unique 10-digit Central Population Register number, date of accreditation, and, where relevant, date of resignation from the Association.

This information was linked to the files of three other registers using the Central Population Register number as the key identifier. The Register contains information on place of birth, marital and vital status (date of death, emigration, or disappearance) from 1968 for all Danish residents in addition to the date of birth of all children born in 1935 and thereafter $(83.1 \%$ of the nurses). Of the 92140 female nurses identified, 9131 (9.9\%) had died, $11(0.01 \%)$ had disappeared, and $2825(3.1 \%)$ had emigrated during the follow-up period from 1980-2003.

The history of employment for each nurse was reconstructed from the nationwide pension fund (Arbejdsmarkedets Tillægspension), membership of which has been compulsory for all Danish wage earners aged 18-66 years since 1964. The fund holds information at the corporate level for each employment held, including start and end dates, company name and a unique 8-digit corporate number. Each company has further been classified according to a 5-digit extension of the International Standard Industrial Classification (11). The information is maintained after retirement or death of the individual in question. No information was available for 1318 nurses (1.4\%) who were self-employed or permanently out of the workforce, leaving employment histories for 90822 nurses.

All cancer cases reported between April 1980 and December 2003 were identified by linkage to the nationwide Danish Cancer Registry, which contains information on the diagnosis - classified by an extended Danish version of the 7th revision of the International Classification of Diseases (ICD 7) - and dates of all cancer cases in Denmark between 1943 and 2003; the registry is considered to be almost complete (12).

In order to compare the nurses with other women in the workforce with regard to social variables (eg, number of children, age at birth of first child, and marital status), we extracted a random sample of 91878 women from the general Danish population in the Central Population Register. All the women in the comparison group were employees (information obtained from the pension fund) and were frequency matched to the nurses by year of birth.

\section{Occupational exposure indicators}

To investigate whether hospital work (which most often involves shift work) affected the risk of breast cancer, on the basis of information from the pension fund, we calculated the cumulated duration of hospital work into the following six groups: $<1$ year, $1-4$ years, $5-9$ years, $10-14$ years, $15-24$ years, and $>25$ years.

Until the early 1970s, all women who were admitted to Danish nursing schools were obliged to sign a statement of physical and psychological health (13). Nurses who were accredited before 1970 may therefore have a different risk behavior (eg, related to alcohol consumption, tobacco smoking, reproduction) than nurses accredited thereafter. In order to investigate differences in cancer risk among different generations of nurses, we categorized them by date of accreditation: prior to 1970 , 1971-1981, and after 1981. We also analyzed data on nurses who had resigned prematurely from the Danish Nurses' Association and been employed within a year, as documented by a subsequent registration in the pension fund, in another profession unrelated to nursing $(\mathrm{N}=6948)$.

Person-years at risk were accumulated for each individual from April 1980 (or at a later date of accreditation) until the date of diagnosis of all forms of cancers, death, disappearance, emigration, or end of follow-up on 31 December 2003 (whichever came first). When the date of accreditation was missing $(1.3 \%)$, it was considered to be the date of birth plus 24 years, as this was the mean age of accreditation for the whole group.

We calculated standardized incidence ratios (SIR) as the ratio of the observed number of cancer cases to the expected number: (person-years at risk during the followup period in each 5-year age and calendar year group) $\times$ (corresponding incidence rates in the general Danish female population). We calculated $95 \%$ confidence intervals $(95 \% \mathrm{CI})$ for the SIR intervals under the assumption that the observed number of cases followed a Poisson distribution (14). Finally, in order to make internal comparisons and adjust for potential confounders, we used a multiplicative Poisson regression model to estimate relative risks of breast cancer in the sub-cohort (1 150690 person-years) of nurses born in 1935 and thereafter. Person-years was summarized in a multidimensional table defined by categories of attained age (12 categories: $<35$ years, 35-39 years, $40-44$ years, $45-49$ years, 50-54 years, 55-59 years, 60-64 years, 65-69 years, $70-74$ years, $75-79$ years, $80-84$ years, $\geq 85$ years), and calendar time (5 categories: 1980-1984, 1985-1989, 1990-1994, 1995-1999, 2000-2003). We included the following in the models as potentional confounders: (i) age at birth of first child ( 4 categories: $<20$ years, 20 24 years, $25-29$ years, $\geq 30$ years), (ii) number of children (5 categories: $0,1,2,3, \geq 4$ ), (iii) place of birth (Copen- 
hagen, Århus and Odense, provincial towns, remaining country, born abroad), and (iv) marital status (4 categories: married, unmarried, divorced, widow).

\section{Results}

Table 1 shows the social variables of Danish nurses and those of other employed Danish women in the general population of the same age. The nurses had an average of 1.86 children, compared to an average of 1.73 in the general female population, and the proportion of nulliparous women was lower among nurses than in the comparison group. The average age at birth of the first child was 27.1 and 25.4 years for the nurses and general female samples, respectively.

We identified 8410 primary cancers in the cohort, representing 1.48 million person-years, and two or more primary cancers in 361 nurses. The overall SIR for all

Table 1. Social characteristics in 2003 of 91878 female Danish registered nurses born 1900-1981 and a random sample of 91878 female Danish employees with the same birth year distribution.

\begin{tabular}{|c|c|c|c|c|}
\hline \multirow[t]{2}{*}{ Characteristic } & \multicolumn{2}{|c|}{$\begin{array}{l}\text { Female nurses } \\
(N=91 \text { 878) }\end{array}$} & \multicolumn{2}{|c|}{$\begin{array}{l}\text { Female employees } \\
\qquad(N=91 \text { 878) }\end{array}$} \\
\hline & $\mathrm{N}$ & $\%$ & $\mathrm{~N}$ & $\%$ \\
\hline \multicolumn{5}{|l|}{ Vital status } \\
\hline Alive & 80173 & 87.3 & 78030 & 84.9 \\
\hline Dead & 8870 & 9.6 & 10802 & 11.8 \\
\hline Disappeared & 11 & 0.01 & 68 & 0.1 \\
\hline Emigrated & 2824 & 3.1 & 2978 & 3.2 \\
\hline \multicolumn{5}{|c|}{ Marital status (before death) } \\
\hline Married & 56804 & 61.8 & 51088 & 55.6 \\
\hline Not married & 17899 & 19.4 & 18774 & 20.5 \\
\hline Divorced & 9231 & 10.1 & 11889 & 12.9 \\
\hline Widowed & 7944 & 8.7 & 10127 & 11.0 \\
\hline \multicolumn{5}{|l|}{ Children a } \\
\hline None & 11710 & 15.3 & 14583 & 19.1 \\
\hline 1 & 11749 & 15.4 & 13507 & 17.7 \\
\hline 2 & 32759 & 42.9 & 31315 & 41.0 \\
\hline 3 & 16307 & 21.4 & 12920 & 16.9 \\
\hline$\geq 4$ & 3825 & 5.0 & 4025 & 5.3 \\
\hline Total fertility rate & $1.86^{b}$ & & $1.73^{c}$ & \\
\hline \multicolumn{5}{|c|}{ Age at birth of first child d } \\
\hline$<20$ years & 1820 & 2.8 & 8917 & 14.4 \\
\hline 20-24 years & 21381 & 33.1 & 24633 & 39.9 \\
\hline $25-29$ years & 30253 & 46.8 & 19829 & 32.1 \\
\hline$\geq 30$ years & 11186 & 17.3 & 8387 & 13.6 \\
\hline
\end{tabular}

a Women born $\geq 1935$ (83.1\%).

${ }^{\mathrm{b}}$ Based on 142187 children and 76350 nurses.

c Based on 132294 children and 76350 women.

d Mean age for Danish female nurses was 27.1 years and 25.4 years for female employees. cancers was 1.0 (95\% CI 0.98-1.0) (table 2). Significantly increased SIR were observed for breast cancer (SIR 1.1, 95\% CI 1.1-1.2), skin melanoma (SIR 1.2, 95\% CI 1.1-1.3), other skin cancer (SIR 1.2, 95\% CI 1.1-1.2), and cancers of the brain and nervous system (SIR 1.2, 95\% CI 1.1-1.3). Significantly decreased SIR were seen for a number of alcohol-related cancers (of the buccal cavity, pharynx, esophagus, colon, rectum, liver, and larynx), with an overall SIR of 0.9 (95\% CI 0.9-0.97) (data not shown). When we included breast cancer in the analysis of alcohol-related cancers, the SIR was increased to $1.1(95 \%$ CI 1.0-1.1). We also observed significantly decreased SIR for tobacco-related cancers (of the lung, buccal cavity, pharynx, larynx, esophagus, pancreas, urinary bladder, kidney, nasal cavities, stomach, liver, uterine cervix, and myeloid leukemia), with

Table 2. Observed and expected numbers of selected cancers among 92140 female Danish nurses, 1980-2003. (SIR = standard incidence ratio; $95 \% \mathrm{CI}=95 \%$ confidence interval; ICD 7 = International Classification of Diseases, 7th revision;)

\begin{tabular}{|c|c|c|c|c|}
\hline Type of cancer & Observed & Expected & SIR & $95 \% \mathrm{Cl}$ \\
\hline $\begin{array}{l}\text { All malignant neoplasms } \\
\text { (ICD 7: 140-205) }\end{array}$ & 8410 & 420.32 & 1.0 & $0.98-1.0$ \\
\hline $\begin{array}{l}\text { Buccal cavity and pharynx } \\
\text { (ICD 7: 140-148) }\end{array}$ & 95 & 102.39 & 0.9 & $0.8-1.1$ \\
\hline $\begin{array}{l}\text { Digestive organs and peritoneum } \\
\text { (ICD 7: 150-159) }\end{array}$ & 1164 & 1289.38 & 0.9 & $0.9-0.96$ \\
\hline Colon (ICD 7: 153) & 537 & 544.73 & 0.99 & 1.1 \\
\hline Esophagus (ICD 7: 150) & 27 & 41.33 & 0.7 & $0.4-0.95$ \\
\hline Stomach (ICD 7: 151) & 86 & 108.25 & 0.8 & $0.6-0.98$ \\
\hline Liver (ICD 7: 155) & 21 & 43.62 & 0.5 & $0.3-0.7$ \\
\hline Rectum (ICD 7: 154) & 211 & 233.52 & 0.9 & $0.8-1.03$ \\
\hline $\begin{array}{l}\text { Respiratory system } \\
\text { (ICD 7: 160-164) }\end{array}$ & 500 & 770.46 & 0.7 & $0.6-0.7$ \\
\hline Larynx (ICD 7: 161) & 13 & 27.68 & 0.5 & $0.3-0.8$ \\
\hline $\begin{array}{l}\text { Lung primary; tracheae } \\
\text { (ICD 7: 162.0.1) }\end{array}$ & 458 & 718.49 & 0.6 & $0.6-0.7$ \\
\hline Breast (ICD 7: 170) & 432 & 2131.77 & 1.1 & $1.1-1.2$ \\
\hline Cervix uteri (ICD 7: 171) & 222 & 374.48 & 0.6 & $0.5-0.7$ \\
\hline Corpus uteri (ICD 7: 172) & 359 & 352.79 & 1.0 & $0.9-1.1$ \\
\hline Ovary (ICD 7: 175) & 378 & 361.92 & 1.0 & $0.9-1.2$ \\
\hline Urinary system (ICD 7: 180-181) & 286 & 339.06 & 0.8 & $0.8-0.95$ \\
\hline Kidney (ICD 7: 180) & 117 & 144.11 & 0.8 & $0.7-0.97$ \\
\hline $\begin{array}{l}\text { Bladder including papilloma } \\
\text { (ICD 7: 181) }\end{array}$ & 169 & 194.95 & 0.9 & $0.7-1.01$ \\
\hline Melanoma of skin (ICD 7: 190) & 395 & 325.73 & 1.2 & $1.1-1.3$ \\
\hline Other skin (ICD 7: 191) & 1488 & 1292.15 & 1.2 & $1.1-1.2$ \\
\hline Eye (ICD 7: 192) & 20 & 18.95 & 1.2 & 0.7 .1 .8 \\
\hline $\begin{array}{l}\text { Brain and nervous system } \\
\text { (ICD 7: 193) }\end{array}$ & 320 & 272.60 & 1.2 & $1.1-1.3$ \\
\hline Thyroid (ICD 7: 194) & 76 & 60.20 & 1.3 & $0.99-1.6$ \\
\hline $\begin{array}{l}\text { Lymphatic and hematopoietic tissue } \\
\text { (ICD 7: 200-205) }\end{array}$ & 417 & 411.72 & 1.0 & $0.9-1.1$ \\
\hline Hodgkin's disease (ICD 7: 201) & 40 & 31.10 & 1.3 & $0.9-1.8$ \\
\hline Leukemia (ICD 7: 204) & 128 & 40.35 & 0.9 & $0.8-1.1$ \\
\hline $\begin{array}{l}\text { Other and unspecified sites } \\
\text { (ICD 7: 199) }\end{array}$ & 64 & 101.81 & 0.6 & $0.5-0.8$ \\
\hline
\end{tabular}


an overall SIR of 0.7 (95\% CI 0.7-0.8). Decreased SIR for alcohol- and tobacco-related cancer were seen in all generations of nurses covered (data not shown).

Table 3 shows the SIR for breast cancer, cancers of the brain and nervous system, thyroid cancer, skin melanoma, and other skin cancers by date of accreditation, birth cohort, and duration of employment. The SIR for breast cancer were similarly significantly elevated across all generations. The relative risk increased by $10-30 \%$ with duration of employment; however, the analyses showed no clear pattern, with the highest risk among nurses who had worked 5-9 years and the lowest among those who had worked $<5$ years.

We observed a $40-70 \%$ increase in risk for cancers of the brain and nervous system for nurses who were accredited after 1981, born after 1955, and employed for $\leq 9$ years as a nurse.

For thyroid cancer, considerable internal differences were observed, with an approximately twofold significant increase in SIR for nurses accredited after 1981 and born after 1955. Furthermore, the SIR was significantly increased by about twofold for nurses who had worked $<10$ years.

For skin melanoma, we found significant and borderline significant elevated SIR across all generations of nurses, the highest being that of nurses accredited after 1971. Furthermore, the SIR was increased in all birth cohorts, however it was mostly insignificant. A $60 \%$ significant increase in risk was seen for the nurses who had worked for $\leq 5$ years, whereas a $40 \%$ increase in incidence ratio was observed for those who had worked for 20-29 years. The risk for other skin cancer followed a similar pattern, with a higher SIR among younger generations of nurses and those with relatively few years of employment.

For cancer of the eye, 16 out of 20 cases were malignant melanomas, with an overall insignificant SIR of $1.2(95 \%$ CI $0.7-1.8)$, a three- to fourfold significant increase in SIR was observed among nurses who were accredited in 1981 or later (SIR 3.2, 95\% CI 1.3-6.6) or born in 1955-1964 (SIR 4.2, 95\% CI 1.7-8.7) (data not shown).

In an internal analysis, table 4 shows the risk of breast cancer by duration of hospital employment - with and without adjustment for reproductive outcome, marital status, and place of birth. A tendency of increasing risk of breast cancer was observed for up to about 25 years of hospital work, whereas no increase in risk was seen for longer durations of employment. Finally, among former members of the Danish Nurses' Association, the SIR for cancer of the respiratory system was $0.4(95 \%$ CI $0.2-0.8)$ and $1.8(95 \% \mathrm{CI}, 1.1-2.8)$ for cancers of the brain and nervous system. The SIR for breast cancer was marginally higher compared to that of current members of the Association (SIR 1.2, 95\% CI 0.97-1.5); former members differed from current members in showing no decrease in the SIR for alcohol-related cancers [(SIR $1.2,95 \%$ CI 0.96-1.4) data not shown]. We found a significant increase in the relative risk for all cancers combined during the first ten years after leaving the

Table 3. Risks for breast cancer, cancers of the brain and nervous system, thyroid cancer, skin melanoma, and other skin cancers by time-related factors among 92140 female Danish nurses, 1980-2003.

\begin{tabular}{|c|c|c|c|c|c|c|c|c|c|c|c|c|c|c|c|}
\hline \multirow[t]{2}{*}{ Time and job type } & \multicolumn{3}{|c|}{ Breast } & \multicolumn{3}{|c|}{ Brain \& nervous system } & \multicolumn{3}{|c|}{ Thyroid } & \multicolumn{3}{|c|}{ Skin melanoma } & \multicolumn{3}{|c|}{ Skin } \\
\hline & Observed & d SIR & $95 \% \mathrm{Cl}$ & Observed & SIR & $95 \% \mathrm{Cl}$ & Observed & SIR & $95 \% \mathrm{Cl}$ & Observed & SIR & $95 \% \mathrm{Cl}$ & Observed & SIR & $95 \% \mathrm{Cl}$ \\
\hline \multicolumn{16}{|l|}{ Date of accreditation } \\
\hline$\leq 1970$ & 1811 & 1.1 & $1.1-1.2$ & 198 & 1.1 & $0.95-1.2$ & 30 & 1.1 & $0.7-1.6$ & 200 & & $0.95-1.3$ & 1137 & 1.1 & $1.1-1.2$ \\
\hline $1971-1980$ & 367 & 1.1 & $1.0-1.2$ & 48 & 1.1 & $0.8-1.5$ & 9 & 0.7 & $0.3-1.4$ & 84 & 1.4 & $1.1-1.7$ & 173 & 1.1 & $0.95-1.3$ \\
\hline$\geq 1981$ & 254 & 1.2 & $1.0-1.3$ & 74 & 1.5 & $1.2-1.9$ & 37 & 1.9 & $1.3-2.5$ & 111 & 1.4 & $1.1-1.6$ & 178 & 1.4 & $1.2-1.6$ \\
\hline \multicolumn{16}{|l|}{ Birth cohort } \\
\hline$\leq 1919$ & 238 & 0.98 & $0.9-1.1$ & 31 & 1.1 & $0.7-1.5$ & 6 & 1.1 & $0.4-2.3$ & 27 & 1.0 & $0.7-1.5$ & 271 & 1.1 & $0.99-1.3$ \\
\hline $1920-1934$ & 720 & 1.1 & $1.1-1.2$ & 85 & 1.1 & $0.9-1.4$ & 12 & 1.2 & $0.6-2.1$ & 77 & 1.1 & $0.9-1.4$ & 441 & 1.1 & $0.96-1.2$ \\
\hline 1935-1944 & 706 & 1.2 & $1.1-1.3$ & 64 & 1.1 & $0.8-1.4$ & 11 & 1.2 & $0.6-2.1$ & 80 & 1.2 & $0.9-1.5$ & 348 & 1.2 & $1.1-1.4$ \\
\hline $1945-1954$ & 517 & 1.1 & $1.1-1.3$ & 62 & 1.2 & $0.9-1.5$ & 6 & 0.4 & $0.2-0.95$ & 95 & 1.3 & $1.0-1.5$ & 233 & 1.1 & $0.96-1.3$ \\
\hline $1955-1964$ & 219 & 1.1 & $0.96-1.3$ & 56 & 1.4 & $1.1-1.9$ & 29 & 1.8 & $1.2-2.6$ & 78 & 1.3 & $0.99-1.6$ & 156 & 1.4 & $1.2-1.6$ \\
\hline$\geq 1965$ & 32 & 1.2 & $0.8-1.7$ & 22 & 1.7 & $1.0-2.5$ & 12 & 2.0 & $1.04-3.5$ & 38 & 1.5 & $1.1-2.0$ & 39 & 1.5 & $1.1-2.1$ \\
\hline \multicolumn{16}{|c|}{ Duration of employment as a nurse (years) } \\
\hline$<5$ & 25 & 0.8 & $0.5-1.1$ & 23 & 1.5 & $0.9-2.2$ & 15 & 2.3 & $1.3-3.8$ & 44 & 1.6 & $1.1-2.1$ & 25 & 0.98 & $0.6-1.5$ \\
\hline $5-9$ & 191 & 1.3 & $1.1-1.5$ & 47 & 1.5 & $1.1-2.0$ & 22 & 1.7 & $1.1-2.6$ & 63 & 1.3 & $0.96-1.6$ & 125 & 1.5 & $1.2-1.8$ \\
\hline $10-19$ & 217 & 1.0 & $0.9-1.2$ & 32 & 1.1 & $0.7-1.5$ & 7 & 0.8 & $0.3-1.6$ & 48 & 1.0 & $0.8-1.4$ & 90 & 1.0 & $0.8-1.3$ \\
\hline $20-29$ & 640 & 1.2 & $1.1-1.3$ & 58 & 1.1 & $0.8-1.4$ & 8 & 0.7 & $0.3-1.4$ & 97 & 1.4 & $1.1-1.7$ & 249 & 1.1 & $0.95-1.2$ \\
\hline$\geq 30$ & 1359 & 1.1 & $1.1-1.2$ & 160 & 1.1 & $0.96-1.3$ & 24 & 1.2 & $0.8-1.8$ & 143 & 1.1 & $0.9-1.3$ & 999 & 1.2 & $1.1-1.2$ \\
\hline All & 2432 & 1.1 & $1.1-1.2$ & 320 & 1.2 & $1.1-1.3$ & 76 & 1.3 & $0.99-1.6$ & 395 & 1.2 & $1.1-1.3$ & 1488 & 1.2 & $0.1-1.2$ \\
\hline
\end{tabular}


nursing profession. In contrast, 10 years after leaving the profession, the relative risk was at the same level or lower than among those who continued working as a nurse. A similar tendency was found for breast cancer risk (table 5).

\section{Discussion}

In this large cohort study of registered nurses, representing almost 1.5 million person-years at risk, we found increased relative risks for breast cancer, cancers of the brain and nervous system, skin melanoma, and other skin cancer. We also found increased risks for cancers of the thyroid and the eye in the youngest generation of nurses, who had worked for $\leq 9$ years. We found decreased relative risks for tobacco- and alcohol-related cancers, excluding breast cancer.

In accordance with previous studies of registered nurses $(6,8,15-19)$, we found an increased risk for breast cancer. Although the mechanisms through which estrogens cause cancer are not fully clear (21), the most important, currently recognized risk factors for breast cancer seem to be related to them (20) [ie, a late first pregnancy, number of children, being nulliparous and not lactating, early menarche, late menopause, use of contraceptives and hormone replacement therapy (HRT) as well as alcohol consumption and obesity in postmenopausal women]. As we do not know whether Danish nurses use HRT more frequently than other Danish women, it is difficult to conclude that some of the excess breast cancers were due to HRT. In a register-based, cross-sectional study in Denmark on socioeconomic status and the use of postmenopausal HRT, Olesen et al (22) found no substantial socioeconomic gradient in Denmark. Therefore, there is no reason to assume that Danish nurses differ noticeably from other Danish women with the same socioeconomic status in terms of HRT usage (22).

The increased incidence of breast cancer among nurses might be due to reproductive factors, such as parity and age at the time of first full-term pregnancy. The older age of the nurses, compared to other female employees when having their first child, might partly explain the high breast cancer incidence, although the higher total fertility rate of the nurses speaks against this. Alcohol consumption is associated with an increased risk of breast cancer (23). Although we found a SIR of 1.1 (95\% CI 1.0-1.1) for all alcohol-related cancers, the SIR was decreased when breast cancer was excluded from the analyses, indicating that female Danish nurses drink less alcohol than other working Danish women. In view of the conflicting results in relation to reproductive pattern and hormonal factors (including the pattern for alcohol-related cancers), it is doubtful that the increased relative risk for breast cancer is due solely to these risk factors. Exposure to light at night, involving disturbance of the circadian rhythm (eg, by shift work) has been reported to be related to breast cancer $(5,24)$. In the internal Poisson regression analysis of breast cancer risk where we adjusted for reproduction, the most serious potential confounder, we observed the highest relative risk among the subgroup with 5-14 years employment in hospitals (relative risk 1.7-1.8), whereas nurses with $>25$ years employment at hospitals tended to have a decreased risk. This might be explained by a healthy worker effect (25), where nurses working long-term in hospitals may be a selected group who can cope with shift work, for example. Actually, we found that former members of the Danish Nurses' Association who leave nursing-related jobs and pursue other professions (eg, because of problems with unavoidable shift work) have a significantly increased risk of breast cancer the first 10 years after leaving the job. Another explanation for the reduced risk of breast cancer in long-term employed nurses might be that they work in hospital departments with little or no shift work. On the other hand, the present results are in contrast to results from a similar registry-based study of Norwegian nurses, where nurses with $>30$ years employment at hospitals, and anticipated to

Table 4. Relative risk of breast cancer for nurses, born in 1935 and later, by duration of employment in hospitals. ( $R R=$ relative risk, $95 \% \mathrm{Cl}=95 \%$ confidence interval, Ref $=$ reference)

\begin{tabular}{|c|c|c|c|c|c|c|}
\hline \multirow[t]{2}{*}{$\begin{array}{l}\text { Duration of } \\
\text { employment }\end{array}$} & \multirow[t]{2}{*}{ Observed } & \multirow{2}{*}{$\begin{array}{c}\text { Number } \\
\text { of } \\
\text { person } \\
\text { years }\end{array}$} & \multicolumn{2}{|c|}{$\begin{array}{l}\text { Age and calendar } \\
\text { time adjusted }\end{array}$} & \multicolumn{2}{|c|}{$\begin{array}{l}\text { Multivariate } \\
\text { adjustment }{ }^{a}\end{array}$} \\
\hline & & & $\mathrm{RR}$ & $95 \% \mathrm{Cl}$ & $\mathrm{RR}$ & $95 \% \mathrm{Cl}$ \\
\hline$<1$ years & 29 & 27850 & 1 & Ref & 1 & Ref \\
\hline $1-4$ years & 89 & 87967 & 1.4 & $0.9-2.1$ & 1.4 & $0.9-2.1$ \\
\hline $5-9$ years & 210 & 157596 & 1.7 & $1.1-2.5$ & 1.8 & $1.1-2.6$ \\
\hline $10-14$ years & 262 & 211067 & 1.6 & $1.1-2.3$ & 1.7 & $1.1-2.5$ \\
\hline 15-24 years & 567 & 433078 & 1.2 & $0.8-1.7$ & 1.3 & $0.9-1.9$ \\
\hline$\geq 25$ years & 264 & 233152 & 0.7 & $0.5-0.99$ & 0.7 & $0.5-1.1$ \\
\hline
\end{tabular}

a Number of children, age at first child, marital status, and place of birth (all categorical).

Table 5. Relative risk for all cancers and breast cancer specifically by time since leaving the nursing profession. (SIR = standardized incidence ratio, $95 \% \mathrm{Cl}=95 \%$ confidence interval)

\begin{tabular}{|c|c|c|c|c|c|c|}
\hline \multirow{2}{*}{$\begin{array}{l}\text { Time since } \\
\text { leaving } \\
\text { nursing }\end{array}$} & \multicolumn{3}{|c|}{ All cancers } & \multicolumn{3}{|c|}{ Breast cancer } \\
\hline & Observed & SIR & $95 \% \mathrm{Cl}$ & Observed & SIR & $95 \% \mathrm{Cl}$ \\
\hline$<5$ years & 31 & 2.7 & $1.8-3.9$ & 10 & 2.9 & $1.4-5.3$ \\
\hline $5-9$ years & 98 & 1.6 & $1.3-2.0$ & 24 & 1.4 & $0.9-2.1$ \\
\hline 10-14 years & 60 & 0.9 & $0.7-2.0$ & 20 & 1.1 & $0.7-1.7$ \\
\hline$\geq 15$ years & 106 & 0.9 & $0.7-1.3$ & 35 & 1.0 & $0.7-1.4$ \\
\hline
\end{tabular}


have had shift work, had significantly more than double the relative risk of breast cancer compared to nurses who did not work at hospitals (26). Given the current evidence for shift work and breast cancer, and since most of the nurses had worked at night for various periods, this is likely to explain at least some of the modest increase in breast cancer incidence found in this study.

The tasks and occupational exposures of nurses vary widely. In hospitals, nurses may be exposed to numerous potential hazards, whereas nurses employed in primary healthcare would be expected to avoid exposure to most carcinogens found in hospitals. In a case-referent study nested in a cohort, Gunnarsdottir et al (7) examined occupational risk factors for breast cancer among Icelandic nurses. After adjusting for year of birth, breast cancer in first-degree relatives, marital status, and nulliparity, they found that working in primary healthcare protected against breast cancer. One limitation of our study is that the pension fund started registering employees only in 1964. It is, therefore, possible that some of the older nurses worked in professions with potential exposure to health hazards prior to 1964 . Furthermore, as all student nurses are trained in hospitals, some may have been exposed to potential carcinogens during training, which will result in misclassification of exposure and probably an attenuation of the risk estimates.

Some studies have indicated an association between occupational exposure to ionizing radiation and increased risks for cancers such as breast cancer and leukemia (27, 28), as well as skin cancer (29), although the findings are not consistent $(30,31)$. Brain cancer has also been hypothesized to be associated with occupational exposure to ionizing radiation (32-34). The use of ionizing radiation for diagnosis and treatments is not restricted to radiology departments but may also occur in specialist wards, such as cardiology, vascular surgery, general surgery, gastroenterology, urology, and traumatology $(35,36)$. In-ward use of ionizing radiation usually requires that medical personnel stand next to the patient. It is standard practice that the staff wear lead aprons for protection, but the high dose rates and the heavy workload can result in exposure of unshielded persons or unprotected parts of the body such as the extremities, the head, and the eyes (35).

Unlike some other studies of nurses $(6,8,18)$, ours showed significantly elevated risks for cancers of the thyroid, brain and nervous system, and the eye among nurses born after 1955 and accredited after 1981. These sites, especially the glandular thyroid, are very sensitive to radiation $(37,38)$. A large cohort study of work-related cancer in the Nordic countries showed elevated risks for brain and thyroid cancers among registered nurses in Denmark, Finland, and Norway, with a decreased risk for thyroid cancer and an increased risk for brain cancer in Sweden (15). It has been estimated that about $10 \%$ of registered nurses are potentially exposed to ionizing radiation in their work (36). Thus, some of the nurses in this study, especially those working in hospital wards where in-ward ionizing radiation is often used in diagnosis or treatment, may have been exposed. Further studies are needed on the risks for brain, eye, and thyroid cancer in relation to the type of ward and sector, especially among hospitals nurses. Although several studies have found increased risks for leukemia among nurses (39), none were observed in this study.

We found increased risks for skin melanoma and other skin cancers which have also been reported as being related to occupational exposure to ionizing radiation (29). Further, 16 of 20 eye cancers were melanomas, which may suggest the same risk factors as the skin melanomas. Although cancer of the skin is caused predominantly by exposure to the sun, occupational exposure to antineoplastic drugs has also been reported to be associated with skin cancer (3). A study of Norwegian nurses found a trend for an increasing incidence of skin melanoma with time since first employment (8). Unlike most known occupational risk factors, with the exception of ionizing radiation, exposure to sunlight can cause both skin melanoma and other skin cancers. When the incidence of both cancers is elevated, it is therefore not possible to distinguish between the potential contributions from ionizing radiation and a greater exposure to sunlight among nurses compared to the general female population.

The strengths of this study were its nationwide approach - covering virtually all female nurses in Denmark - and the fact that we were able to reconstruct the history and duration of employment back to 1964 for almost all the nurses. One crucial limitation, however, was that we did not have information on a number of potential confounders, such as smoking, alcohol use, physical activity, menopausal status, or use of HRT. Nevertheless, nurses in Denmark are expected to have good morale and health so that they act as role models for the general public in terms of smoking, drinking, eating, exercise, and sexual habits (13). Additionally, Friis et al (40) found that Danish nurses were more than twice as physically active and reported higher intake of fruit than the general female population. Our study reflected this behavior, showing a low incidence of alcohol-related cancers when breast cancer was excluded from the analysis and a considerably lower incidence of tobacco-related cancers. Decreased risks for tobaccoand alcohol-related cancers have also been seen in other studies of nurses in the Nordic countries $(6,8,15,18$, $39)$. It is, therefore, likely that Danish nurses drink alcohol and smoke less than other Danish women and that many of the cancers cases found in this study are not associated with known alcohol- and tobacco-related risk factors. 
The increased risks of cancers might also be due to nurses having an earlier diagnosis than non-nurses. Friis et al (40) found that Danish nurses were in contact with a practicing specialist or outpatient clinic almost twice as often and were admitted to hospital over four times as often as the general female population. Enhanced contact with established healthcare facilities probably reflects the better understanding of nurses about illness, diagnosis, and treatment and their easier access to healthcare facilities and physicians; however, the effect would be a lead-time bias and would not reflect real differences in risk.

\section{Concluding remarks}

The overall risk for cancer of female Danish nurses is similar to that of the general Danish female population. The considerably lower risks for tobacco- and alcoholrelated cancers of all generations of nurses are probably due to their healthier past and current lifestyles. The increased risk found for breast cancer has been reported in other studies of nurses; however, we found no clear association between breast cancer risk and duration of employment. The elevated risks for cancers of the breast, thyroid, brain and nervous system, and eye - especially among younger generations of nurses - needs further investigation, with detailed information on the type of work done and occupational exposure to ionizing radiation.

\section{Acknowledgements}

This study was supported by grants from the Danish Nurses' Association and the Danish Cancer Society. The sponsors of the study had no role in the study design, data collection, data analysis, data interpretation, or writing of the report. The corresponding author had full access to all the data for the study and had final responsibility for the decision to submit the manuscript for publication. The authors thank Andrea Meersohn for assistance in data management.

\section{References}

1. International Agency for Research on Cancer (IARC). Ionizing radiation, part 1: $\mathrm{X}$ - and Gamma $(\gamma)$-radiation, and neutrons. Lyon (France): IARC Press; 2000. IARC Monographs on the Evaluation of Carcinogenic Risks to Humans, vol 75.

2. International Agency for Research on Cancer (IARC). Some antiviral and antineoplastic drugs, and other pharmaceutical agents. Lyon (France): IARC Press; 2000. IARC Monographs on the Evaluation of Carcinogenic Risks to Humans, vol 76.

3. International Agency for Research on Cancer (IARC). Some antineoplastic and immunosuppressive agents. Lyon (France): IARC Press; 1981. IARC Monographs on the Evaluation of Carcinogenic Risks to Humans, vol 26.

4. International Agency for Research on Cancer (IARC). Some industrial chemicals. Lyon (France): IARC Press; 1994. IARC Monographs on the Evaluation of Carcinogenic Risks to Humans, vol 60.

5. Straif K, Baan R, Grosse Y, Secretan B, El GF, Bouvard V, et al. Carcinogenicity of shift-work, painting, and fire-fighting. Lancet Oncol 2007;8(12):1065-6.

6. Gunnarsdottir H, Rafnsson V. Cancer incidence among Icelandic nurses. J Occup Environ Med. 1995;37(3):307-12.

7. Gunnarsdottir HK, Aspelund T, Karlsson T, Rafnsson V, V. Occupational risk factors for breast cancer among nurses. Int $\mathrm{J}$ Occup Environ Health. 1997;3(4):254-8.

8. Lie JA, Andersen A, Kjaerheim K. Cancer risk among 43000 Norwegian nurses. Scand J Work Environ Health. 2007;33(1):66-73.

9. Petralia SA, Vena JE, Freudenheim JL, Michalek A, Goldberg MS, Blair A, et al. Risk of premenopausal breast cancer and patterns of established breast cancer risk factors among teachers and nurses. Am J Ind Med. 1999;35(2):137-41.

10. Schernhammer ES, Laden F, Speizer FE, Willett WC, Hunter DJ, Kawachi I, et al. Rotating night shifts and risk of breast cancer in women participating in the nurses' health study. J Natl Cancer Inst. 2001;93(20):1563-8.

11. Statistic Denmark. Erhvervsgrupperingskode: DSE 77 [Occupational codes: DSE 77]. Copenhagen: Statistic Denmark; 1989.

12. Storm HH, Michelsen EV, Clemmensen IH, Pihl J. The Danish Cancer Registry - history, content, quality and use. Dan Med Bull. 1997;44(5):535-9.

13. Pedersen B, Plate C, Sigvaldsen B. Sygeplejersker i mellemkrigstiden: sygepleje i fortid, nutid og fremtid [Nurses in the inter-war period: nursing in past, present and future]. 1995. p 13-27.

14. Breslow NE, Day NE. Statistical methods in cancer research, vol 2: the design and analysis of cohort studies. IARC Sci Publ. 1987;(82):1-406.

15. Andersen A, Barlow L, Engeland A, Kjaerheim K, Lynge E, Pukkala E. Work-related cancer in the Nordic countries. Scand J Work Environ Health. 1999;25 suppl 2:1-116.

16. Pollan M, Gustavsson P. High-risk occupations for breast cancer in the Swedish female working population. Am J Public Health. 1999;89(6):875-81.

17. Pukkala E, Martinsen J, Lynge E, Gunnarsdottir H, Sparen P, Tryggvadottir L, et al. Occupation and cancer - follow-up of 15 million people in five Nordic countries. Acta Oncologica 2009;48:646-790.

18. Rix BA, Lynge E. Cancer incidence in Danish health care workers. Scand J Soc Med. 1996;24(2):114-20.

19. Sankila R, Karjalainen S, Laara E, Pukkala E, Teppo L. Cancer risk among health care personnel in Finland, 1971-1980. Scand 
J Work Environ Health. 1990;16(4):252-7.

20. Velie EM, Nechuta S, Osuch JR. Lifetime reproductive and anthropometric risk factors for breast cancer in postmenopausal women. Breast Dis. 2005;24:17-35.

21. Russo J, Russo IH. The role of estrogen in the initiation of breast cancer. J Steroid Biochem Mol Biol. 2006;102(1-5):89-96.

22. Olesen AV, Johnsen SP, Mortensen JT, Boggild H, Olsen J, Sorensen HT. Socioeconomic status and use of postmenopausal hormone replacement therapy among Danish women. Acta Obstet Gynecol Scand. 2005;84(7):639-44.

23. Baan R, Straif K, Grosse Y, Secretan B, El GF, Bouvard V, et al. Carcinogenicity of alcoholic beverages. Lancet Oncol. 2007;8(4):292-3.

24. Hansen J. Light at night, shiftwork, and breast cancer risk. J Natl Cancer Inst. 2001;93(20):1513-5.

25. Li CY, Sung FC. A review of the healthy worker effect in occupational epidemiology. Occup Med (Lond). 1999;49(4):225-9.

26. Lie JA, Roessink J, Kjaerheim K. Breast cancer and night work among Norwegian nurses. Cancer Causes Control. 2006;17(1):39-44.

27. Weiderpass E, Pukkala E, Kauppinen T, Mutanen P, Paakkulainen H, Vasama-Neuvonen K, et al. Breast cancer and occupational exposures in women in Finland. Am J Ind Med. 1999;36(1):48-53.

28. Cardis E, Vrijheid M, Blettner M, Gilbert E, Hakama M, Hill $\mathrm{C}$, et al. Risk of cancer after low doses of ionising radiation: retrospective cohort study in 15 countries. BMJ. 2005;331(7508):77.

29. Boice Jr JD, Lubin JH. Occupational and environmental radiation and cancer. Cancer Causes Control. 1997;8(3):309-22.

30. Boffetta P, Mannetje A, Zaridze D, Szeszenia-Dabrowska N, Rudnai P, Lissowska J, et al. Occupational X-ray examinations and lung cancer risk. Int J Cancer. 2005;115(2):263-7.

31. Boice Jr JD, Mandel JS, Doody MM. Breast cancer among radiologic technologists. JAMA. 1995;274(5):394-401.
32. Blettner M, Schlehofer B, Samkange-Zeeb F, Berg G, Schlaefer $\mathrm{K}$, Schuz J. Medical exposure to ionising radiation and the risk of brain tumours: interphone study group, Germany. Eur J Cancer. 2007;43(13):1990-8.

33. Phillips LE, Frankenfeld CL, Drangsholt M, Koepsell TD, Van $\mathrm{BG}$, Longstreth Jr WT. Intracranial meningioma and ionizing radiation in medical and occupational settings. Neurology. 2005;64(2):350-2.

34. Carozza SE, Wrensch M, Miike R, Newman B, Olshan AF, Savitz DA, et al. Occupation and adult gliomas. Am J Epidemiol. 2000;152(9):838-46.

35. Covens P, Berus D, Buls N, Clerinx P, Vanhavere F. Personal dose monitoring in hospitals: global assessment, critical applications and future needs. Radiat Prot Dosimetry. 2007;124(3):250-9.

36. Teschke K, Chow Y, Chung J, Ratner P, Spinelli J, Le N, et al. Estimating nurses' exposures to ionizing radiation: the elusive gold standard. J Occup Environ Hyg. 2008;5(2):75-84.

37. Preston-Martin S, Mack WJ. Neoplasms of the nervous system. In: Schottenfeld D, Fraumeni J, editors. Cancer epidemiology and prevention. 2 ed. New York (NY): Oxford University Press; 2008. p 1231-81.

38. Ron E. Thyroid cancer. In: Schottenfeld D, Fraumeni J, editors. Cancer epidemiology and prevention. 2 ed. New York (NY): Oxford University Press; 1996. p 1000-21.

39. Lie JA, Kjaerheim K. Cancer risk among female nurses: a literature review. Eur J Cancer Prev. 2003;12(6):517-26.

40. Friis K, Ekholm O, Hundrup YA. Comparison of lifestyle and health among Danish nurses and the Danish female population: is it possible to generalize findings from nurses to the general female population? Scand J Caring Sci. 2005;19(4):361-7.

Received for publication: 20 January 2009 